\title{
Advice on driving after groin hernia surgery in the United Kingdom: questionnaire survey
}

\author{
Wael Ismail, Stephanie J C Taylor, Emma Beddow
}

Editorial by Amid

Surgical

Directorate,

Havering Hospital

NHS Trust, Harold

Wood Hospital,

Romford RM3 0BE

Wael Ismail

locum consultant

surgeon

Department of

General Practice

and Primary Care,

Queen Mary and

Westfield College,

University of

London, London

E1 4NS

Stephanie J C

Taylor

senior clinical lecturer

in health services

research and

development

Department of

Cardiothoracic

Surgery,

St Bartholomew's

Hospital, London

EC1A 7BE

Emma Beddow

senior house officer in

general surgery

Correspondence to: W Ismail

Wael@ismail.com

BMJ 2000;321:1056
Ambulatory surgery using modern repair techniques has changed the pattern of convalescence after repair of groin hernia by reducing postoperative pain and allowing early mobility. ${ }^{1}$ Driving after herniorrhaphy has potential safety, financial, and social implications. We surveyed the advice given to patients on driving after groin hernia surgery.

\section{Subjects, methods, and results}

In 1998 we sent a questionnaire covering various aspects of hernia repair to a random sample of 200 consultant general surgeons in the United Kingdom selected from a list provided by the Royal College of Surgeons. A similar questionnaire was sent to the general managers of 30 day surgery units randomly selected from a list provided by the British Association of Day Surgery. We report their responses to questions concerning advice on driving after repair of groin hernia (under local or general anaesthesia) and the basis for this advice. We also asked the day units about the provision of written advice. A total of 126 surgeons $(63 \%)$ responded and no reminders were sent. Twenty four questionnaires (19\%) were excluded from the study: in nine the type of repair used was unclear or outdated, ${ }^{2}$ in seven surgeons did too few operations to comment, and in eight surgeons had relocated.

Surgeons' advice ranged from it was all right for patients to drive the same day (three respondents), to patients should wait six to eight weeks before driving (nine respondents), the most common response being that patients should wait two weeks (38) (table). Most surgeons (85) based their advice on common sense and traditional practice; 16 relied on published data to some extent. These 16 surgeons gave advice that varied from driving the next day to waiting three weeks. Laparoscopic surgeons (5) and those who used the Shouldice technique (8) gave advice that varied

Advice on driving given to patients after herniorrhaphy

\begin{tabular}{|c|c|c|c|}
\hline $\begin{array}{l}\text { Recommended convalescence before } \\
\text { patients resume driving }\end{array}$ & $\begin{array}{l}\text { No }(\%) \text { of } \\
\text { all surgeons } \\
(n=102)\end{array}$ & $\begin{array}{l}\text { No of surgeons who stated } \\
\text { their recommendations were } \\
\text { based on published data } \\
\qquad(n=16)\end{array}$ & $\begin{array}{l}\text { Day surgery } \\
\text { units }(n=24)\end{array}$ \\
\hline As soon as they want to/feel comfortable & $5(5)$ & $1(6)$ & - \\
\hline As soon as they can do an emergency stop & $7(7)$ & - & $4(17)$ \\
\hline Same day as operation & $3(3)$ & - & - \\
\hline After 24 hours & - & - & $2(8)$ \\
\hline Next day & $1(1)$ & $1(6)$ & - \\
\hline 2-4 days & $6(6)$ & - & - \\
\hline 5 days & - & $1(6)$ & - \\
\hline 1 week & $6(6)$ & $5(31)$ & $10(42)$ \\
\hline 10 days & $14(14)$ & $4(25)$ & - \\
\hline 2 weeks & $38(37)$ & $2(13)$ & - \\
\hline 2-3 weeks & - & - & $6(25)$ \\
\hline 3 weeks & $5(5)$ & $2(13)$ & - \\
\hline 4 weeks & $8(8)$ & - & - \\
\hline 4-6 weeks & - & - & $2(8)$ \\
\hline 6-8 weeks & $9(9)$ & - & - \\
\hline
\end{tabular}

from driving within 24 hours to desisting for two weeks. The type of anaesthetic used did not seem to influence the advice: 98 surgeons gave the same advice for both local and general anaesthetics. More than a third (37\%) of surgeons failed to respond to the questionnaire.

Twenty four $(80 \%)$ day surgery units responded to the questionnaire and none was excluded. As with the surgeons, advice varied (table). Only two units (8\%) said their advice was based on published data. Nine units $(38 \%)$ did not provide written information about driving and only seven (29\%) documented that this information was given.

\section{Comment}

The advice on when to drive after groin hernia surgery given to patients by general surgeons in the United Kingdom seems to be inconsistent, varying from the day of surgery to two months after surgery. This inconsistency has been described previously. ${ }^{3}$ Even surgeons and day units that rely on published data give variable advice. Many day units do not provide written information on driving after hernia repair or fail to document what information has been given.

Factors that should be considered when advising patients on driving after surgery for a hernia include research evidence, ${ }^{4}$ the medicolegal literature, ${ }^{5}$ the possibility of developing a transient femoral nerve palsy, individual variation in postoperative pain and stiffness, and that patients may have been prescribed opiates. Furthermore, drivers of different types of vehicles need different advice. ${ }^{5}$

Surgeons and day surgery units should be able to provide patients with consistent, evidence-based information (verbal and printed) on driving different types of vehicles after surgery for hernia. National guidelines on this issue should be developed.

We thank Professor Gene Feder for his comments on an early draft of this paper.

Contributors: WI had the original idea for the study, designed the study and the questionnaires, contributed to the analysis and interpretation of the data and wrote the first draft. SJCT contributed to the analysis and interpretation of the data and redrafted the paper for important intellectual content. EB contributed to the analysis and interpretation of the data. WI is guarantor for the study.

Funding: None.

Competing interests: None declared.

1 Amid PK, Shulman AG, Lichtenstein IL. Critical scrutiny of the open "tension-free" hernioplasty. Am J Surg 1993;165:369-71.

2 Royal College of Surgeons of England. Clinical guidelines on the management of groin hernias in adults. London: RCS, 1993.

Robertson GS, Burton PR, Haynes IG. How long do patients convalescence after inguinal herniorrhaphy? Current principles and practice. Ann R Coll Surg Engl 1993;75:30-3.

4 Wright DM, Hall MG, Paterson CR, O'Dwyer PJ. A randomized comparison of driver reaction time after open and endoscopic tension-free inguinal hernia repair. Surg Endosc 1999;13:332-4.

5 Giddins GE, Hammerton A. "Doctor, when can I drive?": a medical and legal view of the implications of advice on driving after injury or operation. Injury 1996;27:495-7.

(Accepted 14 June 2000) 